\title{
Varying importance of the work-life balance dimension of career success for Korean accountants: The effects of gender and generation $^{* *}$
}

\author{
Najung Kim ${ }^{1, *}$, Jaekyoung You ${ }^{1}$, and Eunhyung Lee ${ }^{1}$ \\ ${ }^{1}$ College of Business Administration, Kookmin University, 77 Jungreung-Ro, Seongbuk-Gu, Seoul, \\ 02707, South Korea
}

\begin{abstract}
In this study, we examine the effects of gender, generation, and the interaction between gender and generation on Korean accountants' perception of career success. With the large survey data collected from 1,000 accountants working in South Korea, we found that Korean female accountants have higher perceived importance of work-life balance dimension of career success than male accountants; and younger generations (Millennials or younger) have higher perceived importance for this dimension than older generations (Generation X or older). No interaction effects between gender and generation were found in relation to the perceived importance of work-life balance dimension of career success. Specifically, female accountants had higher perceived importance of work-life balance than their male counterparts regardless of generation; and while the mean was higher for younger generations the gap between the female accountants' means and the male accountants' means of work-life balance dimension has not been reduced. The insignificant interaction effects between gender and generation regarding the perceived level of the work-life balance dimension of career success suggest that, despite the national and organizational efforts in changing the gender discriminating practices, Korean accounting field may still be making a very slow progress in breaking its glass ceiling.

Keywords: Perceived importance of the work-life balance dimension of career success, career, gender differences, generational differences, South Korea, accountants
\end{abstract}

\section{Introduction}

With the abundant research on subjective career success as an important determinant of workrelated outcomes $[1,2]$, several attempts have been made to understand detailed dimensions of subjective career success that were perceived as important by individuals $[3,4]$. Subjective career success builds on the idea that individuals have their own criteria about the desired

\footnotetext{
* Corresponding author: najungkim $@$ kookmin.ac.kr

** This study is a part of « A Study on the Talent Nurturing and Leadership Development of Female Certified Public Accountants » conducted at the request of The Korean Institute of Certified Public Accountants.
} 
form of career and use these criteria to assess the extent to which the current state of their career is successful $[5,2]$.

Reflecting how individuals have various goals that they pursue in relation to their careers [6], scholars have proposed multidimensional notion of subjective career success [7]. The multidimensional notion of career success has drawn various scholars' and practitioners' interests because of its predictability of varying individual and organizational level outcomes as well as its generalizability across multiple cultural contexts [8]. Depending on what their values or desired selves are and what values and ideal selves are imposed on them, individuals can assign varying degrees of importance to each dimension of career success. Building on this notion of career success as a multidimensional construct which can be affected by individual values or orientations, we focus on how the importance of the work-life balance dimension of career success could vary depending on gender or generation or the interaction between the two.

\section{Theoretical Framework}

\subsection{Gender differences in valuing work-life balance as important dimension of career success}

Grounded in the literature on gender roles and stereotypes, several suspect the relationship between gender and the importance of work-life balance dimension. They argue that females would have higher level of importance assigned to the work-life balance dimension of subjective career success because females have traditionally been expected to have stronger orientation for family than work. Furthermore, national contexts can influence the perception of career success [9] and due to the Confucianism-based and paternalistic culture, the gender differences in the perceived importance of the work-life balance dimension of career success may be found strongly especially in the South Korean context.

Since the 1987 Equal Employment Opportunity Act, women's participation in the workforce has consistently been increasing [10]. Employers in both private and public sectors have also implemented family-friendly policies (e.g., on-site childcare centers). However, despite these efforts, gender inequality and underutilization of female talent is still prominent in South Korea. The WEF Gender Gap Report ranked South Korea $102^{\text {nd }}$ out of 144 , which is lower than several male-dominated Asian countries, due to the wide gap in terms of wage, economic participation, and leadership role position [11]. Korean society is heavily grounded in the Confucianism which promotes acceptance of hierarchy, male dominance, collectivism, and a gender-divided family structure $[12,13,14]$; and the burden of childrearing and household chores falls primarily on women. Paired up with the strong emphasis on prioritizing kids' education, Korean women are considered responsible for children's academic achievements [13].

The situation is harsher for working mothers in the gendered workplace where longer work hours and frequent after-work get-togethers that involve heavy drinking are expected of a competent worker [15]. Male-dominant culture constantly corners working mothers to choose between family and work. Thus, faced with the high expectation about competently managing home and work, females in Korea are likely to feel more desperate about balancing work and life in comparison to males in the gendered culture [16].

\subsection{Generational differences in valuing work-life balance as important dimension of career success}

Individuals' work values could vary depending on which generation they belong $[17,18]$ and practitioners and academics have noted that the importance of a certain dimension of career success could vary depending on generation $[19,20]$. Some studies have shown how younger 
generations like Millennials or Gen Xs tend to value leisure and personal life [21]. Younger generations including Millennials scored significantly higher than Boomers on "more vacation time," "work-life balance," and "don't want to work hard" [22, 23, 24]. These results indicate that there could be generational differences in valuing work-life balance dimension of career success.

Similar results were found in the studies on Koreans' work values. Korean Millennials considered leisure, personal time, and work flexibility highly important while the older generations did not perceive so [25]. Furthermore, when asked of the importance of worklife balance, younger generations, in comparison to older generations, perceived work-life balance to be more important in their careers [26]. Overall, younger generations in Korea seem to value work-life balance dimension of career success more than what older generations would value.

Furthermore, extrapolating from the research on how gender stereotypes could be less severe in younger generations than in older generations [27], we would expect the gender differences in work values to be less significant for younger generations. With the growing number of policies and practices regarding work-life balance, the expected difference between female Koreans and male Koreans in their perception of work-life balance dimension as an important dimension of career success may be less prominent for Millennials or younger workers who seem to be less affected by gendered culture than the older generations.

\section{Hypotheses}

Hypothesis 1: There is a significant difference in the perceived importance of the work-life balance dimension of career success between males and females such that females perceive higher importance than do males.

Hypothesis 2: There is a significant difference in the perceived importance of the work-life balance dimension of career success between younger generations and older generations such that younger generations perceive higher importance than do older generations.

Hypothesis 3: There is a significant interaction between gender and generation on the perceived importance of the work-life balance dimension of career success such that the significance difference in the perceived importance of the work-life balance dimension of career success between males and females would be stronger for older generations than for younger generations.

\section{Methodology}

\subsection{Instruments}

We used the career success survey developed by 5C (The Collaboration for the CrossCultural Study of Contemporary Career, [8]) to measure the importance of the work-life balance dimension of subjective career success. Each item started with the following statement, "thinking about my career success, I consider this career dimension as ...," and was measured using a 5-point Likert-type scale (from $1=$ not at all important to $5=$ very important). The items are "achieving balance between work and non-work activities," ("having time for non-work interests," and "achieving a satisfying balance between work and family life." The Cronbach's alpha was 0.71 .

\subsection{Study participants}

We chose KICPA (The Korean Institute of Certified Public Accountants) database to invite those who are currently working in South Korea as accountants. Because the perception of 
career success is not only affected by organizational culture but also by occupational or professional culture [2], we limited the focus to a single profession. Among all the certified accountants registered under KICPA $(20453=7,030+13,423)$, we invited 13,423 accountants who are currently working as certified accountants at an accounting firm to participate in the study. Because the main focus of our study was to investigate gender differences, we kept the online survey link open until we obtained 500 male accountants' and 500 female accountants' responses. We compensated the participants with a 4 USD worth coffee coupon. A majority of them (512 accountants) worked in Big Four accounting firms and the rest worked in medium-sized (the firm size of 100-499), small-sized (the firm size of 2-99), or one-person firm. In terms of their positions at the firm, the sample consisted of 32 associates, 246 seniors, 317 managers, 155 directors, and 250 partners (including the firm owners). In terms of work experience in the field of accounting, 239 had less than 5 years, 312 had 5-10 years of experience, 198 had 10-15 years, 148 with 15-20 years, and 103 with 20+ years of experience in the field. 164 of them were in their 20 s, 490 in their $30 \mathrm{~s}, 255$ in their $40 \mathrm{~s}, 83$ in their 50s, and 8 in their 60s. Among them, 501 had kids and 499 did not.

\section{Results}

Number of kids were known to affect one's perception of work-life balance issues [28] and the size of organization can affect the quality of flexible work arrangements [29]. Thus, childcare responsibilities (yes or no) and organizational size (big4 or not) were added as covariates. Hence, considering these potential covariates, we ran two-way ANCOVA for the set of hypotheses. We used SPSS to run the two-way ANCOVA to test the hypotheses.

Table 1. Descriptive Statistics

\begin{tabular}{|c|c|c|c|c|c|c|}
\hline \multirow{2}{*}{} & \multicolumn{5}{|c|}{ Importance of the work-life balance dimension of career success } \\
\cline { 2 - 7 } & Male & Female & Overall & $\begin{array}{c}\text { Non- } \\
\text { Millennial }\end{array}$ & Millennial* & Overall \\
\hline Mean & 4.0780 & 4.2140 & 4.1460 & 4.0425 & 4.2573 & 4.1460 \\
\hline $\begin{array}{c}\text { Standard } \\
\text { Deviation }\end{array}$ & .57939 & .56761 & .57727 & .56997 & .56479 & .57727 \\
\hline Number & 500 & 500 & 1,000 & 518 & 482 & 1,000 \\
\hline
\end{tabular}

*Millennials were those born after 1985, reflecting the unique generational structure in Korea Source: Authors' current study.

Table 2. ANCOVA Results

(Dependent Variable: Importance of the work-life balance dimension of career success)

\begin{tabular}{|c|c|c|c|c|}
\hline & Mean Square & Df & F & Sig. \\
\hline Child & .101 & 1 & .316 & .574 \\
\hline Big4 & .794 & 1 & 2.479 & .116 \\
\hline Gender & 2.360 & 1 & 7.371 & .007 \\
\hline MilGen & 5.976 & 1 & 18.662 & .000 \\
\hline Gender*MilGen & .117 & 1 & .366 & .545 \\
\hline Error & .320 & 994 & \\
\hline \multicolumn{4}{|c|}{ R Squared = 0.44(Adj. R Squared =0.39) } \\
\hline
\end{tabular}

Notes: $\mathrm{n}=1000$; Child $=$ childcare responsibilities $(\mathrm{no}=0$, yes $=1) ;$ Big4 $=$ firm size (not-Big4 $=0$, Big4 $=1) ;$ Gender $=$ gender $($ male $=0$, female $=1) ;$ MilGen $=$ Millennial generation or younger $($ NonMillennials or older $=0$, Millennials $=1)$.

Source: Authors' current study. 
ANCOVA analysis revealed statistically significant differences between female accountants and male accountants $(\mathrm{F}(1,994)=2.360, \mathrm{p}<.05$, partial $\mathrm{n} 2=.007)$. We found significant differences between the millennial or younger accountants and older accountants $(\mathrm{F}(1,994)=5.976, \mathrm{p}<.05$, partial $\eta 2=.018)$. There was no statistically significant interaction between gender and generation on the importance of work-life balance dimension in career, whilst controlling for organizational size and childcare responsibilities, $\mathrm{F}(1,994)$ $=0.117, \mathrm{p}=.545$, partial $n 2<.000$.

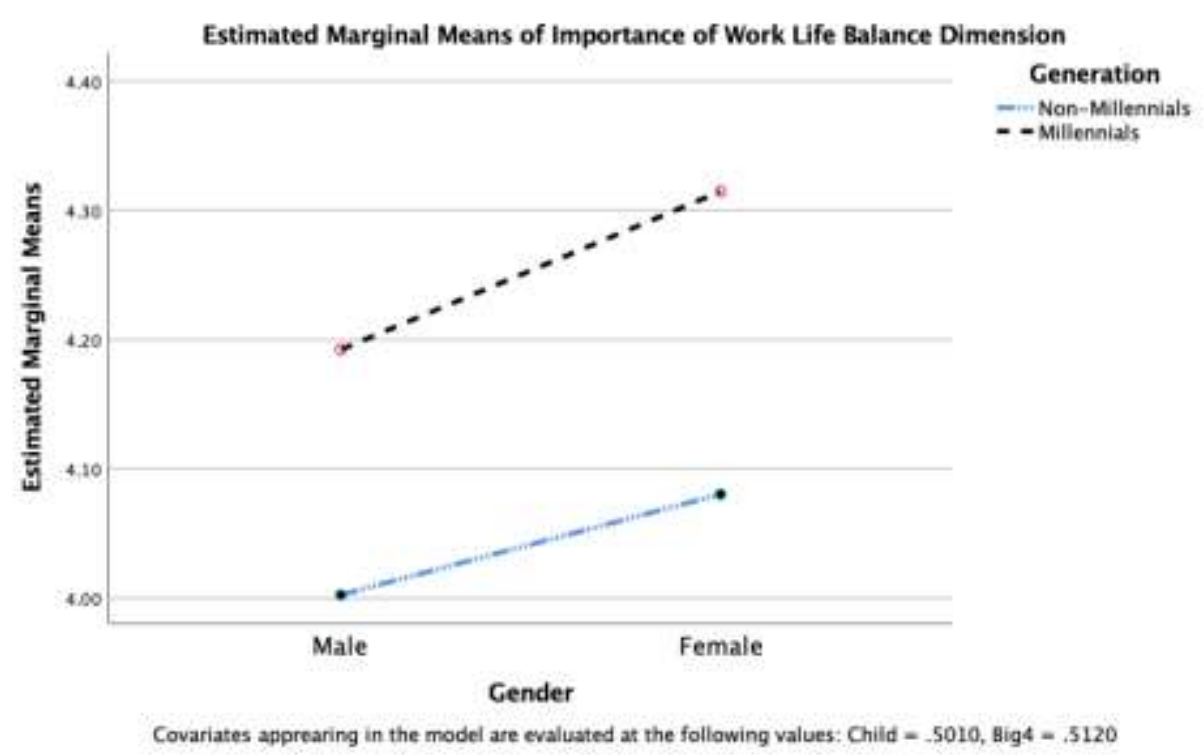

Fig. 1. Estimated marginal means of the importance of work-life balance dimension of career success Source: Authors' current study.

\section{Discussion and Conclusion}

The results supported Hypothesis 1 and Hypothesis 2. Female accountants had higher perceived importance of work-life balance dimension of career success than male accountants. Younger generations (Millennials or younger) had higher perceived importance for the work-life balance dimension of career success than older generations (Generation X or older). The results were consistent with the existing studies on the gender differences and the generational differences in work values and subjective career success. However, the interaction effects between gender and generation on the perceived importance of work-life balance dimension were insignificant (Hypothesis 3 not supported). Younger generations had higher perceived importance for the work-life balance dimension but the gap between younger males and younger females was no different from the gender gap found among older accountants.

While studying the situation in Korea, scholars have noted how Korean employees have trouble utilizing the family-friendly practices because of the male-dominated culture of their organizations [30]. The persistent gap between females and males in their perception of worklife balance as an important dimension of career success regardless of their generations shows that, despite the governmental and organizational efforts in developing family-friendly, gender-equality practices, Korean accounting field may still have a long way to break its glass ceiling. 


\section{References}

1. N. Dries, The meaning of career success: Avoiding reification through a closer inspection of historical, cultural, and ideological contexts. Career Development International, 16(4), 364-384 (2011)

2. P. A. Heslin, Conceptualizing and evaluating career success. Journal of Organizational Behavior, 26(2), 113-136 (2005)

3. J. Pan, W. Zhou, How do employees construe their career success: An improved measure of subjective career success. International Journal of Selection and Assessment, 23(1), 45-58 (2015)

4. K. M. Shockley, H. Ureksoy, O. B. Rodopman, L. F. Poteat, T. R. Dullaghan, Development of a new scale to measure subjective career success: A mixed-methods study. Journal of Organizational Behavior, 37(1), 128-153 (2016)

5. M. B. Arthur, S. N. Khapova, C. P. Wilderom, Career success in a boundaryless career world. Journal of Organizational Behavior, 26(2), 177-202 (2005)

6. B. J. Dik, A. M. Sargent, M. F. Steger, Career development strivings: Assessing goals and motivation in career decision-making and planning. Journal of Career Development, 35(1), 23-41 (2008)

7. N. Dries, R. Pepermans, O. Carlier, Career success: Constructing a multidimensional model. Journal of Vocational Behavior, 73(2), 254-267 (2008)

8. J. P. Briscoe, R. Kaše, N. Dries, A. Dysvik, J. A. Unite, I. Adeleye, ... J. Zikic, Here, there, \& everywhere: Development and validation of a cross-culturally representative measure of subjective career success. Journal of Vocational Behavior, 103612 (2021)

9. A. Smale, S. Bagdadli, R. Cotton, S. Dello Russo, M. Dickmann, A. Dysvik, J. Unite. Proactive career behaviors and subjective career success: The moderating role of national culture. Journal of Organizational Behavior, 40(1), 105-122 (2019)

10. Statistics Korea [online], Available at: http://kostat.go.kr/portal/eng/index.action (2021)

11. World Economic Forum [online], Available at: http://www3.weforum.org/docs/WEF_GGGR_2021.pdf (2021)

12. S. Chaudhuri, S. Park, S. Kim, The changing landscape of women's leadership in India and Korea from cultural and generational perspectives. Human Resource Development Review, 18(1), 16-46 (2019)

13. Y. Cho, G. McLean, I. Amornpipat, W. Chang, G. Hewapathirana, M. Horimoto, M. Lee, J. Li, N. Manikoth, J. Othman, S. Hamzah, Asian women in top management: eight country cases. Human Resource Development International, 18(4), 407-428 (2015)

14. N. Kim, C. Rowley, The changing face of Korean women managers. In Rowley, C. \& Paik, Y. (Eds.). In the changing face of Korean management (pp. 184-209), Routledge, London (2009)

15. Y. Cho, J. Park, S. Han, B. Ju, J. You, A. Ju, C. Park, H. Park, How do South Korean female executives' definitions of career success differ from those of male executives? European Journal of Training and Development, 41(6), 490-507 (2017)

16. F. Cheung, D. Halpern, Women at the top: Powerful leaders define success as work+family in a culture of gender. American Psychologist, 65(3), 182-193 (2010)

17. J. I. C. Hansen, M. E. Leuty, Work values across generations. Journal of Career Assessment, 20(1), 34-52 (2012) 
18. J. M. Twenge, A review of the empirical evidence on generational differences in work attitudes. Journal of Business and Psychology, 25(2), 201-210 (2010)

19. K. Chudzikowski, Career transitions and career success in the 'new' career era. Journal of Vocational Behavior, 81(2), 298-306 (2012)

20. N. Dries, R. Pepermans, E. De Kerpel, Exploring four generations' beliefs about career: Is "satisfied" the new "successful"? Journal of Managerial Psychology, 23(8), 907-928 (2008)

21. J. M. Twenge, S. M. Campbell, B. J. Hoffman, C. E. Lance, Generational differences in work values: Leisure and extrinsic values increasing, social and intrinsic values decreasing. Journal of Management, 36(5), 1117-1142 (2010)

22. K. Smola, C. Sutton, Generational differences:Revisiting generational work values for the new millennium. Journal of Organizational Behavior, 23, 363-382 (2002)

23. J. M. Twenge, S. M. Campbell, Generational differences in psychological traits and their impact on the workplace. Journal of Managerial Psychology, 23, 862-877 (2008)

24. M. Wong, E. Gardiner, W. Lang, L. Coulon, Generational differences in personality and motivation: Do they exist and what are the implications for the workplace? Journal of Managerial Psychology, 23, 878-890 (2008)

25. H. Lee, G. Yu, Work-life balance of Generation Y: The meaning and the role in view of generational work value, Quarterly Journal of Labor Policy, 13(4) 1-31 (2013)

26. H. Lee, Y. Kim, Generational differences in values of life and factors influencing turnover intention among Korean nurses, Journal of Digital Convergence, 19(1) 217$228(2021)$

27. K. E. Cichy, E. S. Lefkowitz, K. L. Fingerman, Generational differences in gender attitudes between parents and grown offspring. Sex Roles, 57(11-12), 825-836 (2007)

28. M. Hilbrecht, S. M. Shaw, L. C. Johnson, J. Andrey, 'I'm home for the kids': contradictory implications for work-life balance of teleworking mothers. Gender, Work \& Organization, 15(5), 454-476 (2008)

29. B. Kotey, I. Koomson, Firm size differences in financial returns from flexible work arrangements (FWAs). Small Business Economics, 56(1), 65-81 (2021)

30. S. Kim, Women and family-friendly policies in the Korean government. International Review of Administrative Sciences, 74(3), 463-476 (2008) 